\title{
Analysis of the interannual variation characteristics of the northernmost drift position of the green tide in the Yellow Sea
}

\author{
Dongxue $\mathrm{Li}^{1,2} \cdot$ Zhiqiang Gao $^{1} \cdot$ Xiangyang Zheng ${ }^{1} \cdot$ Nanyu Wang ${ }^{3}$
}

Received: 11 July 2019 / Accepted: 12 June 2020 / Published online: 25 June 2020

(C) Springer-Verlag GmbH Germany, part of Springer Nature 2020

\begin{abstract}
The green tide in the Yellow Sea is the world's largest macroalgal bloom. The maximum area affected by green tide can reach tens of thousands of square kilometers. Previous studies have shown that green tide drifts northward during the outbreak, yet the location of its northernmost drift and the characteristics of interannual variations have not been explored in detail. In this paper, we use the Moderate Resolution Imaging Spectrometer (MODIS) data, GaoFen-1 (GF-1) satellite data, unmanned aerial vehicle (UAV) aerial data, and field trips for extraction and monitoring of green tide and then analyze the emergence, development, and dissipation of the green tide in Rongcheng coastal waters and the change of the northernmost drift position and its related factors from the year of 2013 to 2018. The results show that green tide have drifted to the Rongcheng coastal area over the years and the northernmost drift position can reach $37.662^{\circ} \mathrm{N}$ in 2014. Interannual difference of the northernmost position of the drift of the green tide is obvious, it is mainly affected by the wind, and there is no certain connection with the maximum coverage area, the coverage area when reaching the northernmost position, and the existence days of the green tide. These results can help to understand the drift range and dissipation process of green tide in the Yellow Sea.
\end{abstract}

Keywords Green tide $\cdot$ Drift position $\cdot$ Rongcheng coastal waters $\cdot$ Dissipation trajectory $\cdot$ Remote sensing $\cdot$ Wind

\section{Introduction}

Green tides (caused by floating Ulva prolifera) have been a marine ecological disaster every summer in China since the outbreak of a large-scale green tide in 2008 (Zhao et al. 2015; Zhou et al. 2015; Yu and Liu 2016). It is a kind of annual green macroalgae and widely distributed in coastal areas all over the world (Zhao 2014). It is not harmful in itself and even has the edible value (Fleurence et al. 1994; Li et al. 2018), but after falling off from objects, it will reproduce rapidly and then drift northward with the wind and sea surface circulation (Lee et al. 2011; Qiao et al. 2011; Xu et al. 2014; Son et al. 2015;

Responsible Editor: Vitor Manuel Oliveira Vasconcelos

Zhiqiang Gao

zqgao@yic.ac.cn

1 Yantai Institute of Coastal Zone Research, Chinese Academy of Sciences, Yantai 264003, China

2 University of Chinese Academy of Sciences, Beijing 100049, China

3 Yantai Meteorological Bureau, Yantai 264003, China
Yuan et al. 2017; Hu et al. 2018; Jin et al. 2018). It will arrive in Shandong Peninsula coastal waters at the end of May and the beginning of June every year (Song et al. 2015). The largescale green tide blooms will alter the marine ecological environment and affect the survival and reproduction of other marine organisms, and even it would affect human activities and physical and mental health of human beings (Lopes et al. 2000; Dahlgren and Kautsky 2004; Nelson et al. 2008).

Drifting is one of the main characteristics of green tides disasters, the Yellow Sea green tide, originating at the Jiangsu Shoal, drifts northward over a long distance. When green tide drifted to Qingdao, Shandong province, most of the green tide algae Ulva prolifera are in the dissipation phase (Zhang et al. 2013), and a large number of microscopic propagules will be released, which will be a risk of biological invasion to this sea area (Zhao et al. 2018). Although large-scale green tides have not yet settled in this area, the range of areas affected by drifting green tides is very large. So, where is the northernmost position of the influence of the Yellow Sea green tide? Will it invade the northern Yellow Sea and affect the northern waters of Weihai, Yantai, which is the location shown in area B in Fig. 1? Smallscale green tide outbreaks have occurred in this area every year since 2007 (Ma et al. 2010; Song et al. 2011). 


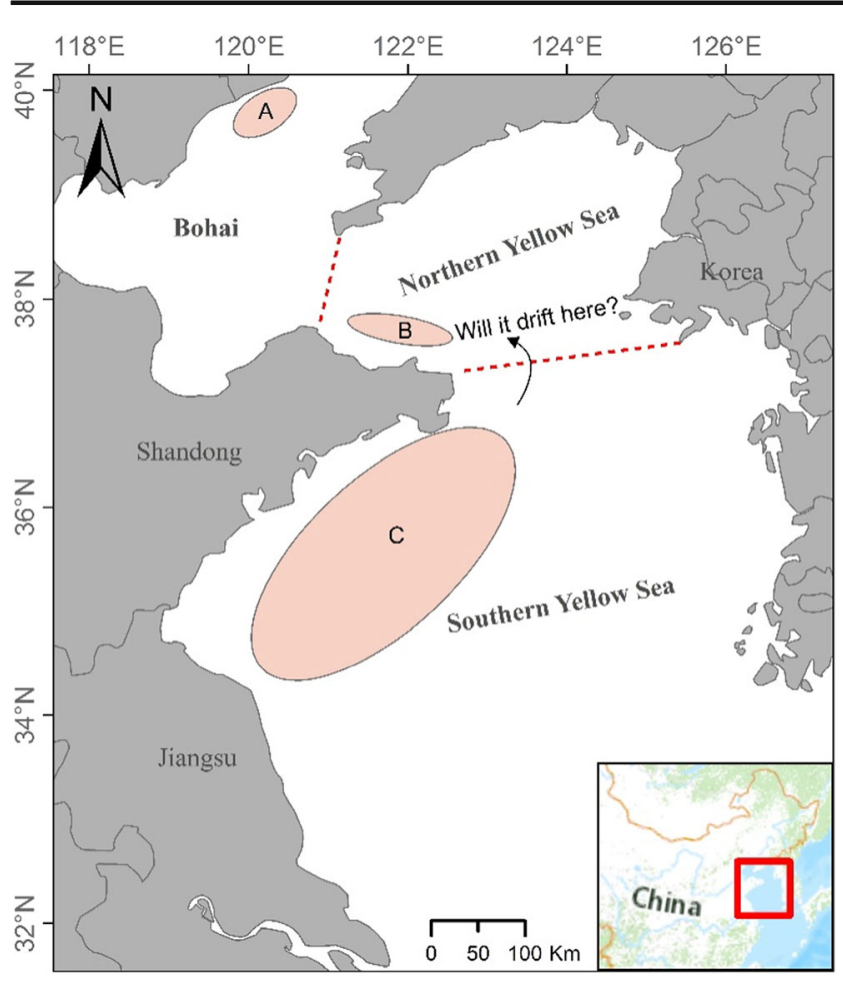

Approximate areas with green tide outbreaks

Fig. 1 Description of green tide outbreak areas in the Yellow Sea and Bohai. The red dash line is the boundary of the Bohai and northern Yellow Sea and the northern Yellow Sea and southern Yellow Sea. Area A has been documented that the origin of the green tides in this area is local (Song et al. 2019). Area C has been documented that the origin of the green tides in this area is at the Jiangsu Shoal of the southern Yellow Sea (Pang et al. 2010; Liu et al. 2013; Zhang et al. 2014). Area B has reported green tide outbreaks since 2007, but the original source is not clear

So in this paper, the main purpose is to analyze the emergence, development, and dissipation of green tide in Rongcheng coastal waters, which is the northernmost sea area affected by green tides. Moreover, the change of the northernmost drift position of green tide and its related factors from the year of 2013 to 2018 will be discussed.

\section{Materials and methods}

\section{Data acquisition}

The satellite remote sensing data include GaoFen-1 WFV (GF-1) data and the Moderate Resolution Imaging Spectrometer (MODIS) Terra/Aqua data, downloaded from the China Centre For Resources Satellite Data and Application and the National Aeronautics and Space Administration (NASA), respectively. The resolution of GF1 and MODIS is $16 \mathrm{~m}$ and $250 \mathrm{~m}$. According to the growth and drift characteristics of green tide, all MODIS and GF-1 satellite images in the green tide distribution area $\left(30-38^{\circ} \mathrm{N}\right.$, 119-127º) from May to August of 2013-2018 were screened, and the cloudless or partially cloudy images were selected as shown in Table 1. The accuracy of MODIS and GF-1 is basically the same in the areas with high density of green tide coverage, and in the areas with low green tide density, the accuracy of GF-1 is higher than that of MODIS (Xu et al. 2017). So in this study, MODIS data is mainly used to analyze the drift process of green tide, and the GF-1 data is mainly used to analyze the process of the northernmost position during the dissipation period of green tides.

The daily ASCAT (Advanced Scatterometer) sea surface wind (SSW) data was downloaded from the NASA remote sensing system data website (http://www.remss.com), the resolution is $25 \mathrm{~km}$ at the sea surface height of $10 \mathrm{~m}$, and the ASCAT data are very consistent with the buoys and QuickScat data (Bentamy et al. 2008), which can satisfy the accuracy of wind with high precision.

The unmanned aerial vehicle (UAV) data comes from the aerial photography through the Dajiang Inspire $1 \mathrm{UAV}$ equipped with DJI $\times 3$ digital camera, when the green tide arriving at the Roncheng sea area from 6 July 2016 to 19 July 2016.

\section{Data processing}

Because the floating green tide algae contain chlorophyll, its spectral properties are similar to the terrestrial vegetation, which indicates that the absorption in red-light band is stronger and the reflectance in near-infrared band is higher, and it causes that the spectral characteristics are different from that of waters $\mathrm{CHu}$ et al. 2010). Then, the green tide algae and seawater can be clearly distinguished according to the characteristics by means of normalized differential vegetation index (NDVI).

$\mathrm{NDVI}=\frac{\left(\rho_{-} N I R-\rho \_ \text {Red }\right)}{\left(\rho \_N I R+\rho \_\operatorname{Red}\right)}$

The $\rho_{-}$NIR is the near-infrared band reflectance, corresponding to band 2 of MODIS and band 4 of GF-1, and the $\rho_{-}$Red is the red-light band reflectance, corresponding to band 1 of MODIS and band 3 of GF-1. Different NDVI thresholds are adopted to extract green tide according to different water bodies. And the dynamic NDVI threshold method can also be adopted to recognize the green tide algae in areas affected by sun glint and thin clouds.

The level of MODIS data is $1 \mathrm{~B}$, it is calibrated radiances data, and the atmospheric correction and geometric correction are necessary before extracting green tide, and the GF-1 data need radiometric calibration before atmospheric correction, and they all need to be re-projected to the WGS 1984 UTM Zone 51N. The center position of green tide coverage area is extracted by the Arcgis Mean Center tool, the northernmost edge of the distribution range is taken 
Table. 1 Image date observed of green tide from 2013 to 2018

MODIS Terra and Aqua level 1B image date

GF-1 WFV image date

20135 May,12 May,13 May, 28 Jun, 6 Jul, 24 Jul,5 Aug13 May, 15 May, 26 May, 27 May, 12

20 Jun, 24 Jul,13 Aug

2014

Jun, 18 Jun, 28 Jun,14 Jul,21 Jul,4 Aug

4 Jul, 9 Jul, 29 Jul

2015

25 May, 3 Jun, 6 Jun, 12 Jun, 21 Jun,1 Jul,14 Jul,29 Jul,30 Jul

4 Jul, 8 Jul,14 Aug

2016

25 May, 30 May, 17 Jun, 24 Jun, 26 Jun,17 Jul,21 Jul,24 Jul

$29 \mathrm{Jul}$

2017

17 May, 27 May, 4 Jun, 16 Jun, 17 Jun, 26 Jun,12 Jul

9 Jun,29 Jun, 11 Jul,9 Aug

2018

1 Jun, 11 Jun, 12 Jun, 24 Jun,14 Jul,18 Jul,20 Jul,30 Jul,11 Aug

20 Jul, 29 Jul,1 Aug

as the green tide front, and the coverage area is calculated by the number of green tide pixels extracted multiplied by the square of satellite image resolution. The drift position in the Rongcheng coastal area and the coverage of green tide were verified with our UAV data and Green tide bulletin in North China Sea issued by the North China Sea Branch of State Oceanic Administration from 2013 to 2018.

The regional average of wind data is explained as follows: $\bar{u}_{t}=\frac{1}{N} \sum_{\mathrm{i}=1}^{\mathrm{N}} u\left(s_{i}, t\right), \overline{\mathrm{v}}_{t}=\frac{1}{N} \sum_{\mathrm{i}=1}^{\mathrm{N}} v\left(s_{i}, t\right)$. The $\bar{u}_{t}$ and $\overline{\mathrm{v}}_{t}$ indicate the regional average value $(\mathrm{m} / \mathrm{s})$ in component of wind field in east-west direction and north-south direction at time $t$. The $s_{i}$ indicates spatial location $(i=1,2, \ldots \ldots, N)$. The $u\left(s_{i}, t\right)$ and $v\left(s_{i}, t\right)$ indicate the east-west and north-south component $(\mathrm{m} / \mathrm{s})$ of wind field in the position $s_{i}$ at time $t$.

\section{Results}

\section{Analysis of green tide drift and dissipation process}

Green tides are first observed at the coast of Jiangsu Province $\left(32-35^{\circ} \mathrm{N}, 120-124^{\circ} \mathrm{E}\right)$ from May to June, and
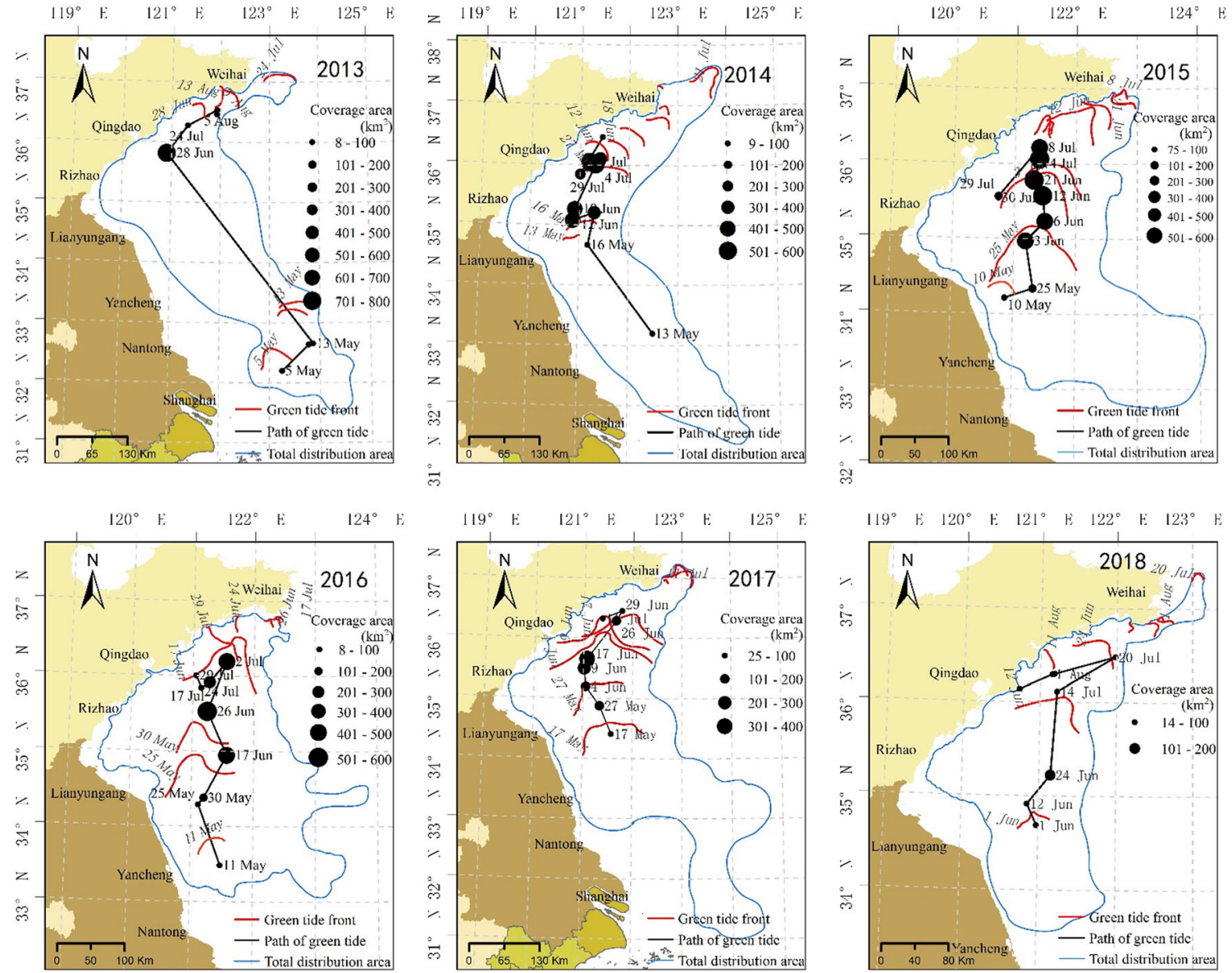

Fig. 2 The green tide of the Yellow Sea drift process from 2013 to 2018. The size of the black dot indicates the coverage area of the green tide, the blue solid line indicates the total distribution range of green tide, the red solid line indicates the green tide front, and the black solid line indicates the green tide drift path 
the coverage area is less than $100 \mathrm{~km}^{2}$, green tide in this phase mostly distributes in small patches and will grow and accumulate rapidly in the next month, and the coverage area will reach its peak with a maximum value of $790 \mathrm{~km}^{2}$ in 2013. Figure 2 shows green tide annual drift process in the Yellow Sea from 2013 to 2018. The black dot in Fig. 2 indicates the central position of the coverage area of green tide, and the size indicates the coverage area, the coverage area of green tide reaches its maximum in the coastal waters of Rizhao in 2016 and 2018 and in Qingdao coastal waters in 2013, 2014, 2015, and 2017; and then, the coverage area decreases as green tide front moves northward (red solid lines and black dots as shown in Fig. 2) and arrives at the Rongcheng coastal waters from the end of June to the beginning of July, Rongcheng is located in the easternmost of Shandong Peninsula and the northernmost sea waters affected by the green tide (See Fig. 3.). Thereafter, the green tide coverage will continue to decrease and eventually disappear from the sea surface from north to south in the first and middle of August.
The range represented by the blue solid line in Fig. 2 indicates the sea waters influenced by the green tide in the process of emergence, outbreak, and dissipation, and there is a slight difference of interannual variation, the easternmost can reach $124.8^{\circ} \mathrm{E}$ in 2017 , and the northernmost position can reach $37.662^{\circ} \mathrm{N}$ in 2014 . The green tides all can drift to the Rongcheng coastal waters from 2013 to 2018 , and they all have entered the sea area before and after the peak period of blooms, as illustrated in Table 2, and before that, in May, there was no green tide in Shandong Peninsula.

\section{Analysis of the drift process of green tide in Rongcheng coastal area}

\section{The process of green tide in Rongcheng coastal waters in 2016}

The maximum coverage area of the green tide in the Yellow Sea reaches $554 \mathrm{~km}^{2}$ in 2016 observed by the MODIS, and the corresponding observation date is 26 June. The date of green
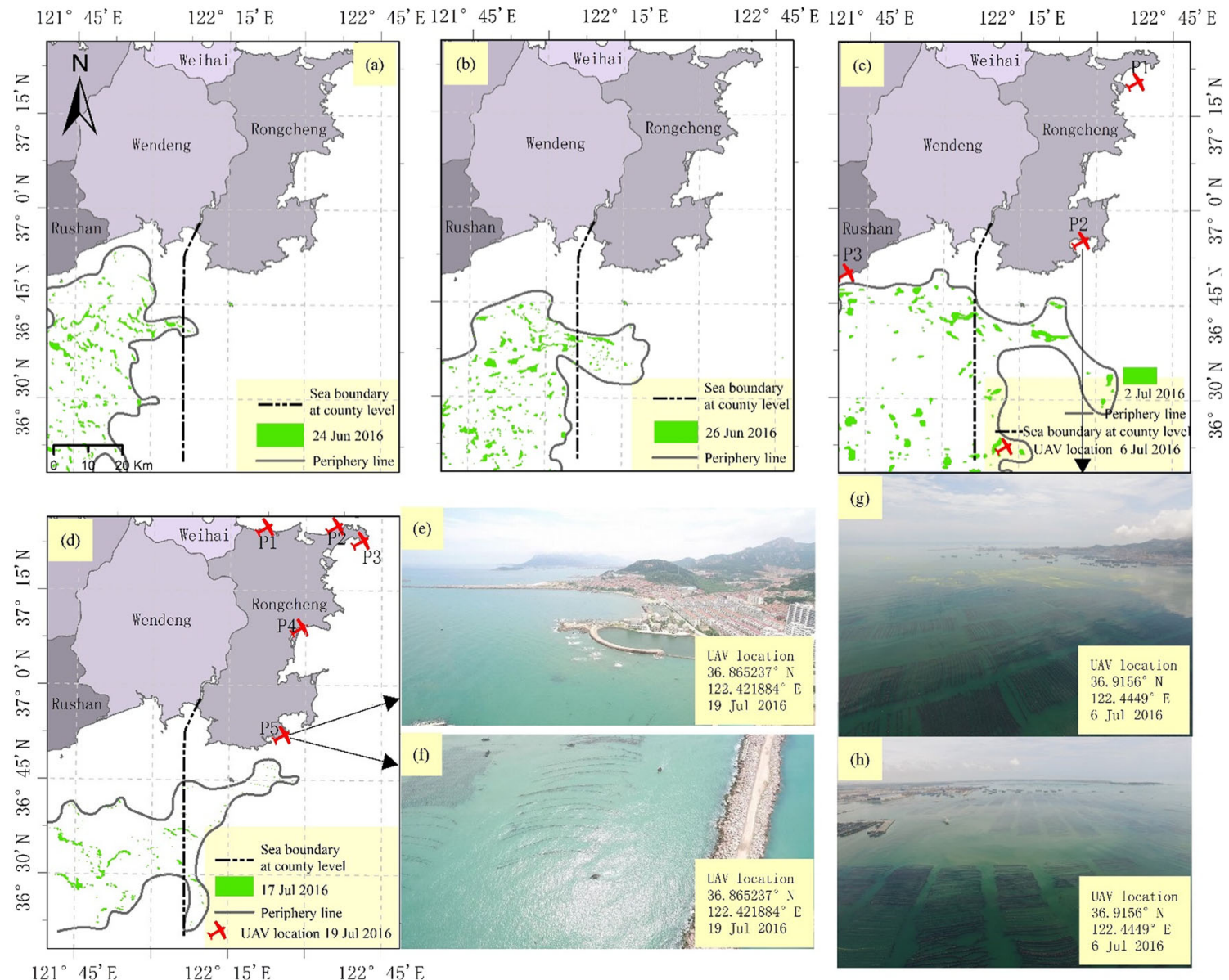

Fig. 3 The green tide emergence, development, and dissipation process in Rongcheng coastal waters in 2016. a-d Green patches are green tide acquired by MODIS. Panels e $-\mathrm{h}$ are acquired by the UAV, among them, $\mathrm{e}$ and $f$ are obtained on 19 July, and the image shows no distribution of green tide, and $\mathrm{g}$ and $\mathrm{h}$ are obtained on 6 July, and the red ellipse in panel

$\mathrm{g}$ has a small distribution of green tide, and there has no distribution of green tide in panel $\mathrm{h}$. The black dash line is the sea boundary between Rushan and Rongcheng, and the gray solid line indicates the periphery line of green tide distribution 


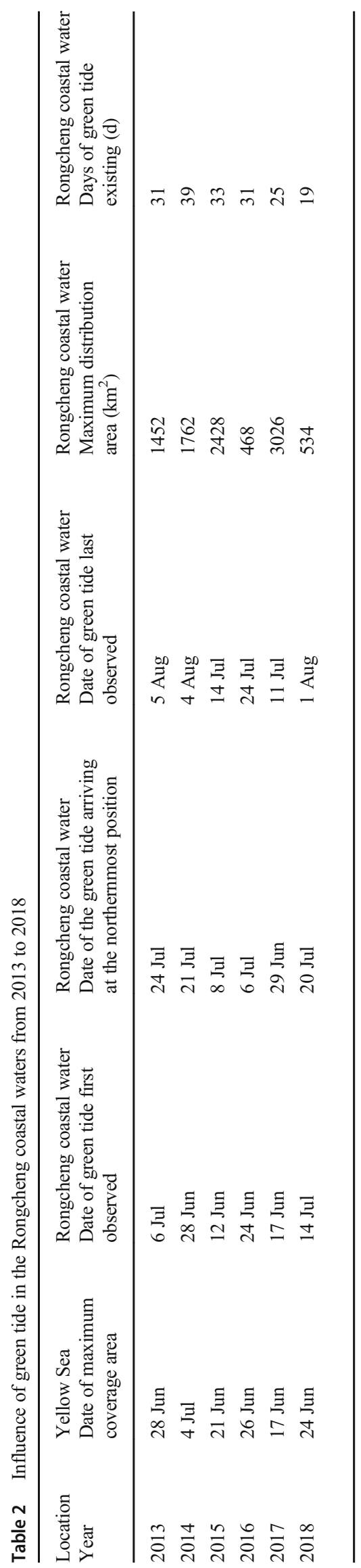

tide beginning to influence the Rongcheng coastal waters is 24 June, and the corresponding coverage area in Rongcheng coastal waters is about $1.1 \mathrm{~km}^{2}$, and the boundary of Rongcheng coastal waters is illustrated in Fig. 3. As we can know from the Fig. 4, the coverage area of the green tide in the whole Yellow Sea is gradually decreasing after 26 June, the green tide area entering into the Rongcheng coastal waters first increases, and it reaches the peak on $65 \mathrm{~km}^{2}$ on 2 July, then it gradually decreases, and finally, the coverage area of green tide in the Rongcheng coastal waters observed is about $11 \mathrm{~km}^{2}$ until 17 July.

Satellite image shows that the Shidao coastal area $\left(36.914^{\circ}\right.$ $\mathrm{N}, 122.435^{\circ} \mathrm{E}$ ), which is the position shown in Fig. 3(d) P5, is not influenced by the green tide in 2016, but by the field research and UAV aerial photography, there still exists sporadic green tide patches which have invaded into the marine aquaculture area. As shown in the UAV aerial photography on 6 July (Fig. $3 g$ and h), the northernmost position of the green tide influence range reaches the coastal waters of Chengshantou, which is located in the P1 position in the Fig. 3. This observation is also consistent with the location of the green tide described by Green tide bulletin in North China Sea. Most of the green tide algae are in the distribution of small patches or sporadic strips, and some even float between the floating balls in kelp cultivation areas, and the corresponding coverage area is about tens square meters to hundreds of square meters. The distribution area and the sea area influenced have started to decrease in the Rongcheng coastal waters, as shown in the satellite image on 17 July (Fig. 3(d); there is no distribution of green tide in the northern sea waters of Shidao, the P1-P5 in the Fig. 3(d), in combination with the UAV aerial photography observed on 19 July (Fig. 3d, e and $\mathrm{f}$ ); and the influence of green tide to the Rongcheng coastal waters is then finished.

Through the monitoring of the dissipation phase of green tide in the Rongcheng coastal waters by the UAV, the reliability of satellite data is further verified, and it is also shown that the UAV can be adopted as an auxiliary tool to improve the satellite monitoring accuracy.

\section{The process and influence of green tide in the Rongcheng coastal waters in 2013-2018}

The interannual difference of the distribution position of green tide in the Rongcheng coastal waters is obvious from 2013 to 2018, but the drift and dissipation regular pattern is basically the same, which indicates that it drifts from the south to north in the early stage of blooms, and then it gradually recedes southward after reaching the northernmost position (Fig. 5).

The northernmost position influenced by green tide over these years is between the $37.027^{\circ} \mathrm{N}$ in 2015 and $37.662^{\circ} \mathrm{N}$ in 2014 , the green tide in this phase is mainly in the small patches, and the sea areas with green tide are tongue-shaped; when it has reached the northernmost position, the green tide 
Fig. 4 Comparison of green tide coverage area acquired by MODIS in Rongcheng coastal waters and Yellow Sea in 2016

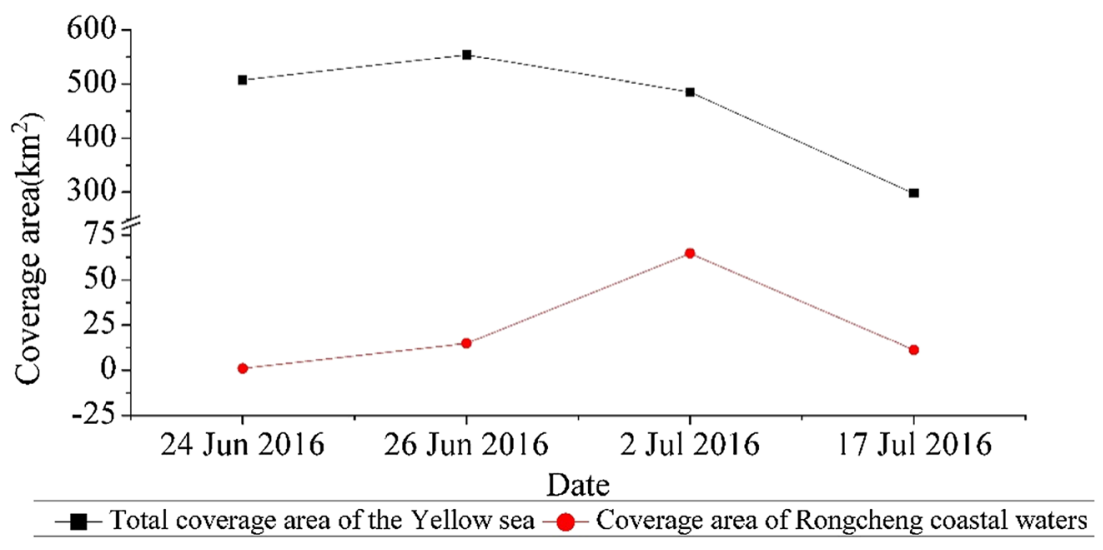

front drifts from north to south, and it gradually recedes in the next few days. But in 2015, the date of the last observation of the green tide distribution in the Rongcheng sea waters is 8 July, and it is also the date of the green tide arriving the northernmost position; it was attributed to the fact that we cannot observe the green tide from the satellite within a few days after 8 July 2015, and until 14 July, the green tide has disappeared from the Rongcheng coastal sea surface, and it goes backs to the south of $36.6^{\circ} \mathrm{N}$.
The drift direction of the green tide in the Rongcheng coastal waters is mainly in the northeast, and through our observations, the green tide has not crossed the Chengshantou coastal waters and drifted to the coastal area of the north of Yantai and Weihai.

Green tides begin to influence the Rongcheng coastal waters from the late of June to early of July and finishes the influence in the mid-late of July to early of August, the average influence period is about 30 days, the maximum area
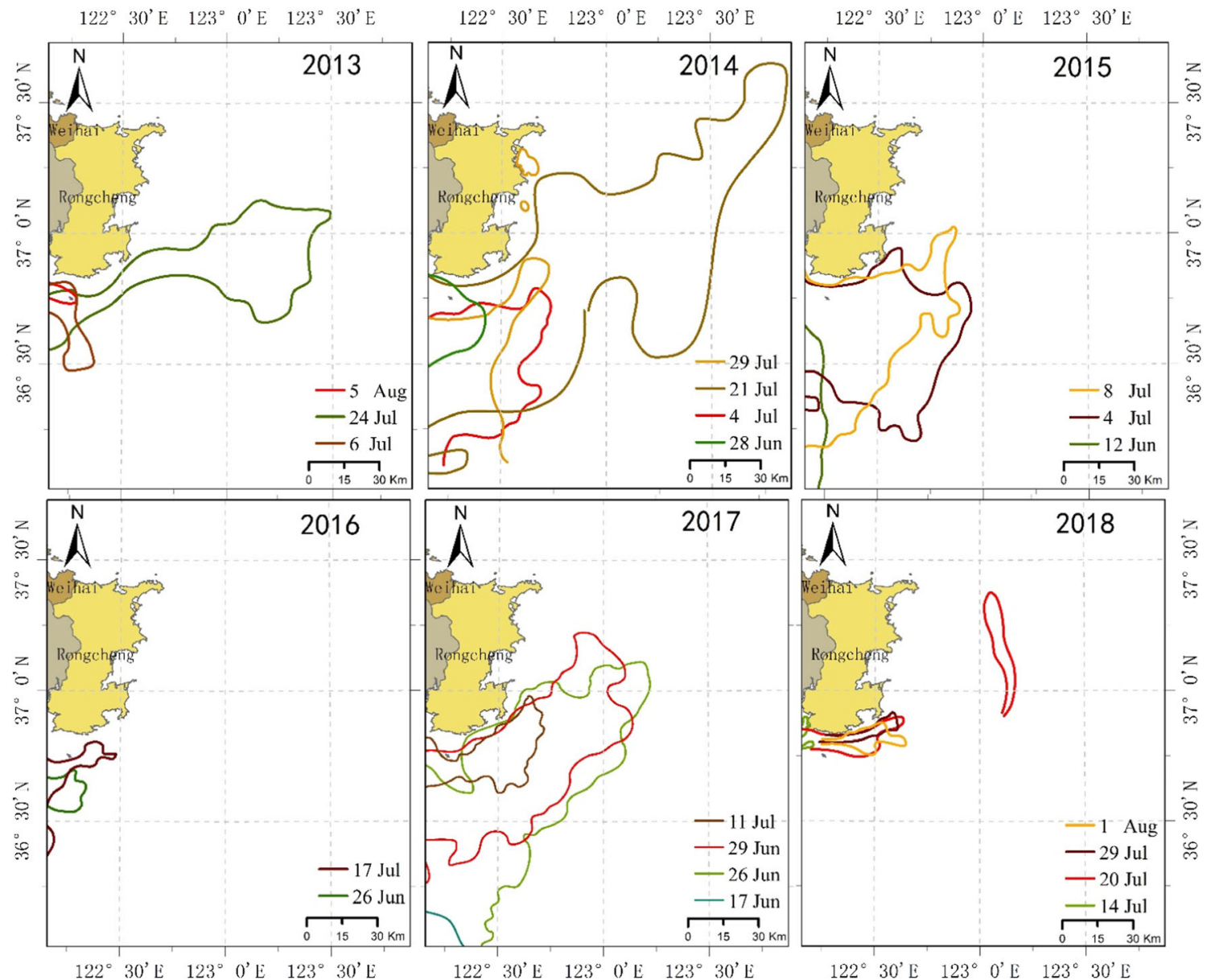

Fig. 5 Distribution of green tide in the Rongcheng coastal waters. Solid lines of different colors indicate the distribution range of green tide on different dates 
influenced by the green tide can reach $3026 \mathrm{~km}^{2}$ in 2017, and the minimum value is $468 \mathrm{~km}^{2}$ in 2016 (Table 2.).

\section{The relationship between the characteristics of green tide and drift position}

Through the analysis of the maximum coverage area of green tide, the coverage area when the green tide arriving at the northernmost position, the days of the green tide existing (Fig. 6a) and the northernmost position (Fig. 6b) over these years, we found that there is no connection between the above characteristics and drift position of green tide. Generally, the more maximum coverage area is, the longer the days of existence are, and there is no relationship between the coverage area when the green tide arriving at the northernmost position, the maximum coverage area of green tide, and the days of existence (Table 3). When the date of arriving at the northernmost position is later, the corresponding ratio of the coverage area and the maximum coverage area is relatively smaller. When it has arrived at the northernmost position, the longitudinal and latitudinal positions have similar trends over these years. This indicates that when the green tide drifts northward, it will also drift eastward.

We know that we have carried out a lot of green tide algae collection work, whether before the green tide algae entered the sea or before the outbreak in 2017 and 2018, which makes the coverage of these 2 years shows a significant downward

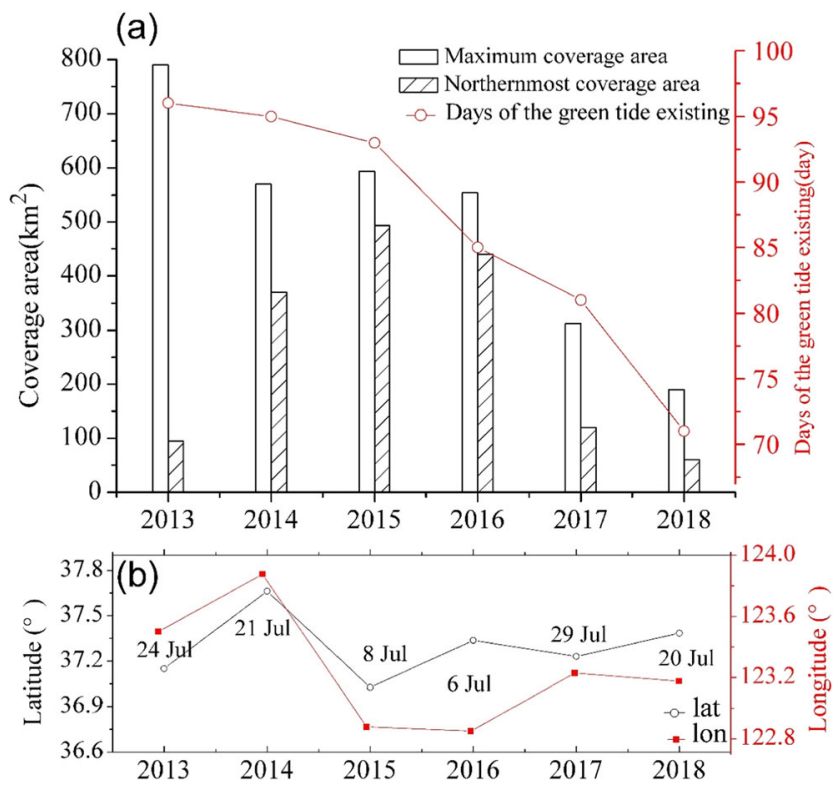

Fig. 6 The relationship between the coverage area, days of existence, and drift position of green tide. a The maximum coverage area of green tide in the Yellow Sea, the coverage area when it has drifted to the northernmost position and the days of existence. b The longitude and latitude information of the green tide drifting to the northernmost position over these years trend compared with previous years. This makes the days of the existence of green tides and the days affecting the Rongcheng coastal waters less than the average of previous years, but has no obvious effect on the northernmost position.

\section{The relationship between wind and drift position}

First, we will take 2016 as an example, compared with the green tide range observed by satellite on 24 June, the green tide drifts to the east for about $8 \mathrm{~km}$ entirely on 26 June, and the maximum drift distance is about $17 \mathrm{~km}$, as illustrated in the easternmost position of the green tide peripheral line on 26 June in the Fig. $7 \mathrm{a}$, and the average drift speed is about $5 \mathrm{~km}$ per day. As shown in the average SSW from 24 June to 26 June in this area, the corresponding wind speed is about $6 \mathrm{~m} / \mathrm{s}$, and the direction is east to south. The direction of green tide drift is about $45^{\circ}$ to the right of the wind direction. This is mainly due to the Ekman drift current. In the northern hemisphere, the Ekman drift current is $45^{\circ}$ to the right of the wind direction (Fig. 7a). The periphery of green tide distribution is shown in Fig. 7b, the entirety has drifted to the northeast from 26 June to 2 July, the average wind direction is northward and slightly westward, and the corresponding wind speed is about $6 \mathrm{~m} / \mathrm{s}$ from 26 June to 2 July, the east-west component of wind speed is about $1.6 \mathrm{~m} / \mathrm{s}$, and the green tide drift to the east for about $15 \mathrm{~km}$ with the average drift speed of $2.5 \mathrm{~km}$ per day. It shows that under the influence of the topography of the sea area and the action of the south or southwest wind, the green tide will bypass the block of land and drift to the north for more distance, and in the east-west direction, the green tide will still drift eastward even if the wind has a very small component of the west component, which is not only due to the influence of Ekman drift current but also the mesoscale anticyclone eddy in the Qingdao-Shidao offshore area and northeastward current in Lunan coast (Fig. 11 current 3 and 4 ), and the surface residual current in the southern offshore area of Shandong Peninsula points to the northeast all year round, so that even under the influence of the weak western component, the green tide drifting to this sea area would still drift to the northeast.

Then, we will analyze the relationship between the wind and the drift of green tide from 2013 to 2018. The green tide drifts to the north, which is the result of influences by the combination of north and east components of wind (Fig. 8). When the north and east components of the wind are positive and the days when the wind speed is larger are more, the green tide will drift farther north, which it can reach the $37.662^{\circ} \mathrm{N}$ in 2014. In combination with the average wind (Fig. 9), the monthly mean wind in the Rongcheng Sea in June 2014 is dominated by the westerly wind, which has caused the green tide to move offshore after entering the Rongcheng coastal area in late June. The wind in July is mainly northerly, and the wind speed is more than $5 \mathrm{~m} / \mathrm{s}$, which makes the green tide 
Table 3 The correlation between the position of green tide drift and its influencing factors

\begin{tabular}{|c|c|c|c|c|c|}
\hline & Maximum coverage area & Northernmost coverage area & Days of the green tide existing & Latitude & Longitude \\
\hline Pearson Corr. & 1 & 0.38427 & 0.92337 & 0.20672 & -0.23101 \\
\hline Sig. & - & 0.45196 & 0.00858 & 0.69434 & 0.65965 \\
\hline Pearson Corr. & 0.38427 & 1 & 0.47584 & -0.30165 & 0.00308 \\
\hline Sig. & 0.45196 & - & 0.3401 & 0.56125 & 0.99539 \\
\hline Pearson Corr. & 0.92337 & 0.47584 & 1 & 0.37577 & -0.10175 \\
\hline Sig. & 0.00858 & 0.3401 & - & 0.46287 & 0.84789 \\
\hline Pearson Corr. & 0.20672 & -0.30165 & 0.37577 & 1 & 0.63327 \\
\hline Sig. & 0.69434 & 0.56125 & 0.46287 & - & 0.17707 \\
\hline Pearson Corr. & -0.23101 & 0.00308 & -0.10175 & 0.63327 & 1 \\
\hline Sig. & 0.65965 & 0.99539 & 0.84789 & 0.17707 & - \\
\hline
\end{tabular}

moving around the land drifts to north for more distance. When the wind speed of the north component is relatively small and the existing days are few, and the wind speed of the west component is relatively large and the existing days are more, the distance of the green tide drifting to the north is closer. In $37.027^{\circ} \mathrm{N}$ of 2015 , the monthly average wind in the Yellow Sea in June 2015 is dominated by the northerly wind, and the average wind speed is more than $5 \mathrm{~m} / \mathrm{s}$, which is slightly higher than that in the same period in 2014, and it makes the time of the green tide entering into the Rongcheng sea waters earlier than 2014, the 12 June and 28 June. Under the influence of northeast surface current, the green tide will still cross the block of Rongcheng land and then drift northeastward, but the drifting distance is less than that of 2014. And the southeast wind has dominated the wind in July 2015, which would make the drifting distance of the green tide to north closer under the influence of the block of land.

In combination with the above analysis, we can know that the northernmost position of green tide drifting has close relationship with the wind, and it is mainly influenced by the combination of north and east components of the wind. Even if the northern component is strong and occurs many times, but without the role of the eastern component, it is difficult for the green tide to cross the land influence and drift far northward, such as in 2013 and 2018. Through the above analysis, it is found that the drift position of green tide in the Rongcheng coastal water is closely related to the wind. In order to further determine the relationship between the wind and the drift position, we choose the beginning of the green tide entering the Rongcheng coastal water (the boundary of the Rongcheng sea area shown in Fig. 3) as the starting point and the northernmost end as the end point to analyze the influence of the component of the wind in the northeast direction $\left(\theta=45^{\circ}\right)$ on the drift position of the green tide during this period. The following is the description of the calculation method of the wind field:

$\overline{\mathrm{U}}=\frac{1}{t} \sum_{t} \bar{u}_{t}$

$\overline{\mathrm{V}}=\frac{1}{t} \sum_{t} \bar{v}_{t}$

where $t$ is the time from entering the Rongcheng coastal water to the northernmost position of the green tide front, and the $t$ value can be calculated from Table $2 . \bar{u}_{t}$ and $\bar{v}_{t}$ represent the regional average of the east-west and north-south components of SSW in the range of $36-38^{\circ} \mathrm{N}$ and $120-124^{\circ} \mathrm{E}$ at
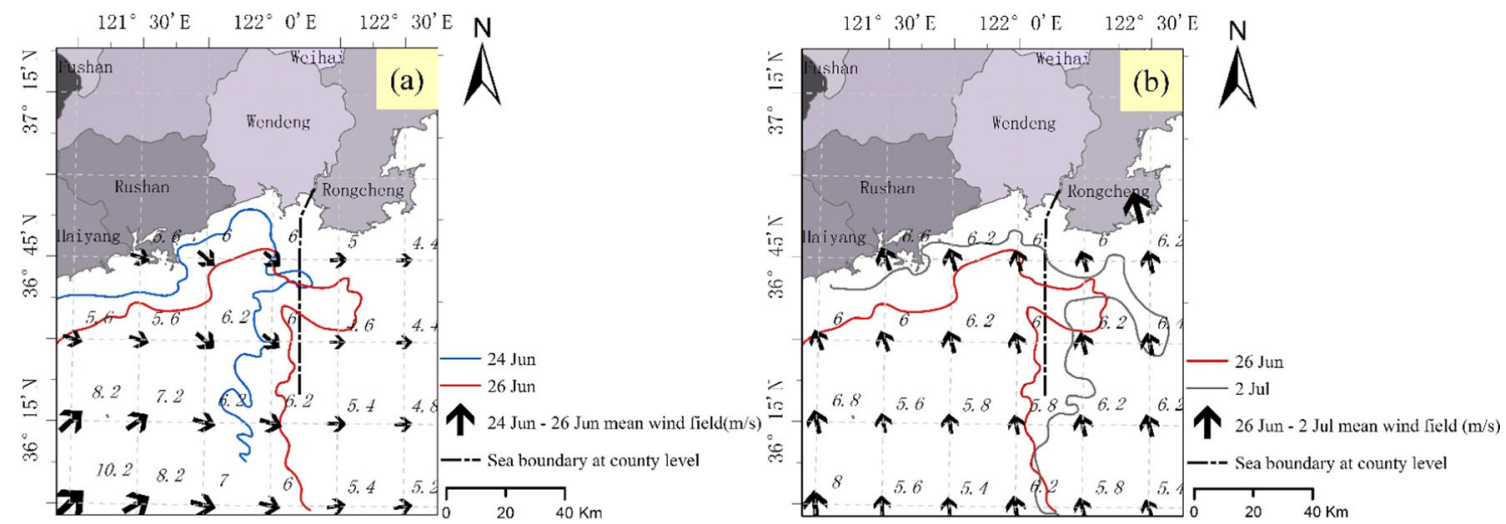

Fig. 7 Relationship between wind and green tide drift path in 2016 
Fig. 8 Daily data of north component and east component of average SSW in the Yellow Sea $\left(34-38^{\circ} \mathrm{N}, 119-124^{\circ} \mathrm{E}\right)$ in June and July from 2013 to 2018 and the latitude information of the drift northernmost position of green tide

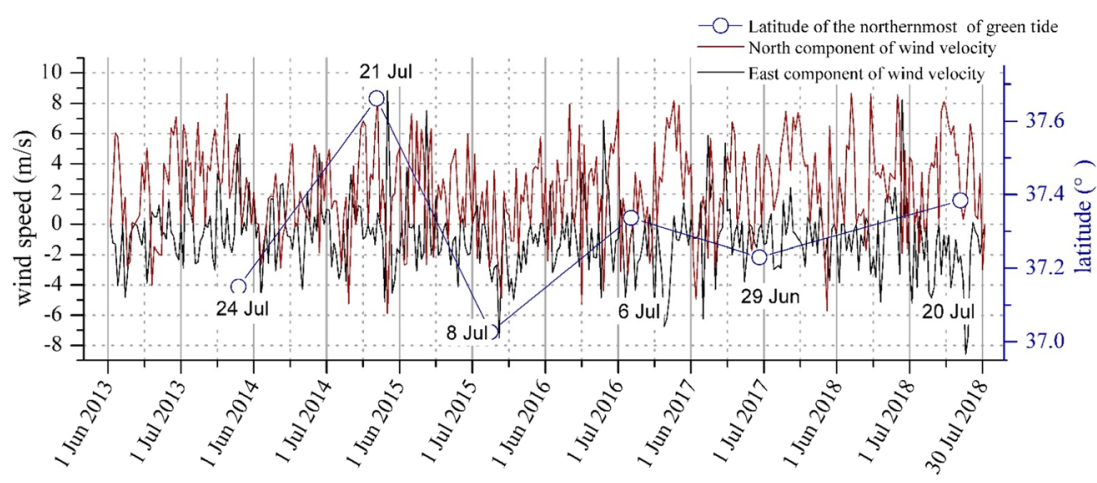

time $t$, and $\bar{U}$ and $\bar{V}$ are the mean values of the east-west and north-south components of the regional average in the time $t$, which can be used to analyze the mean effect of wind over a period of time in the sea area.

$\mathrm{D}=\sum_{t}\left(\bar{u}_{t} * \cos \theta+\bar{v}_{t} * \cos \theta\right)$

where $D$ is the distance of the green tide front drifting from the starting point in $t$ time under the action of the component of the wind in the northeast direction $\left(\theta=45^{\circ}\right)$.

Over the years, the trend of drift distance of green tide under the action of northeast component wind is similar to that of actual drift distance, as shown in Fig. 10. Pearson's correlation coefficient is $0.934, p=0.01$, showing a highly positive correlation. It shows that the drift position difference of the green tide in this sea area is mainly caused by the wind and the relationship between the wind action and the actual drift distance is $y=0.03 * D+61.5\left(R^{2}=0.872\right)$.

Through the analysis of the drift trajectory and wind data of the green tide in the Rongcheng sea waters over these years, the green tide has not crossed $37.4^{\circ} \mathrm{N}$ over most years, and it has reached near $37.662^{\circ} \mathrm{N}$ only in 2014 . Under the influence of wind, the drift direction is mainly northeast, and it eventually recedes southward and disappears from the sea surface in the Rongcheng coastal area. Since 2013, the green tide in the southern Yellow Sea has not drifted northwest crossing the
Chengshantou coastal waters, and it has not drifted to the Yantai and Weihai coastal areas.

\section{Discussion}

Many researchers have analyzed the drift of green tide (Qiao et al. 2011; Xing et al. 2011; Cui et al. 2012; Gao et al. 2014; Li et al. 2014; Bao et al. 2015; Son et al. 2015; Chen et al. 2018; Hu et al. 2018), but the northernmost sea area affected by the green tide has not been thoroughly analyzed. According to the satellite data from 2013 to 2018, it is found that the process of green tide drift in the Rongcheng coastal waters is basically the same. First, it drifts northward continuously and then recedes southward after reaching the northernmost position.

Sheng et al. (2018) use GOCI to analyze the dissipation process in 2015; however, using multi-source data for many years to analyze the characteristics of green tide can better describe the regularity of green tide drift and dissipation.

According to the analysis in this paper, the drift process in the Rongcheng coastal area is closely related to wind, and the relationship between the drift process and sea surface current has not been discussed in details in this paper. However, due to the influence of Lubei coastal current, mesoscale anticyclonic eddy in Qingdao-Shidao offshore, northeastward

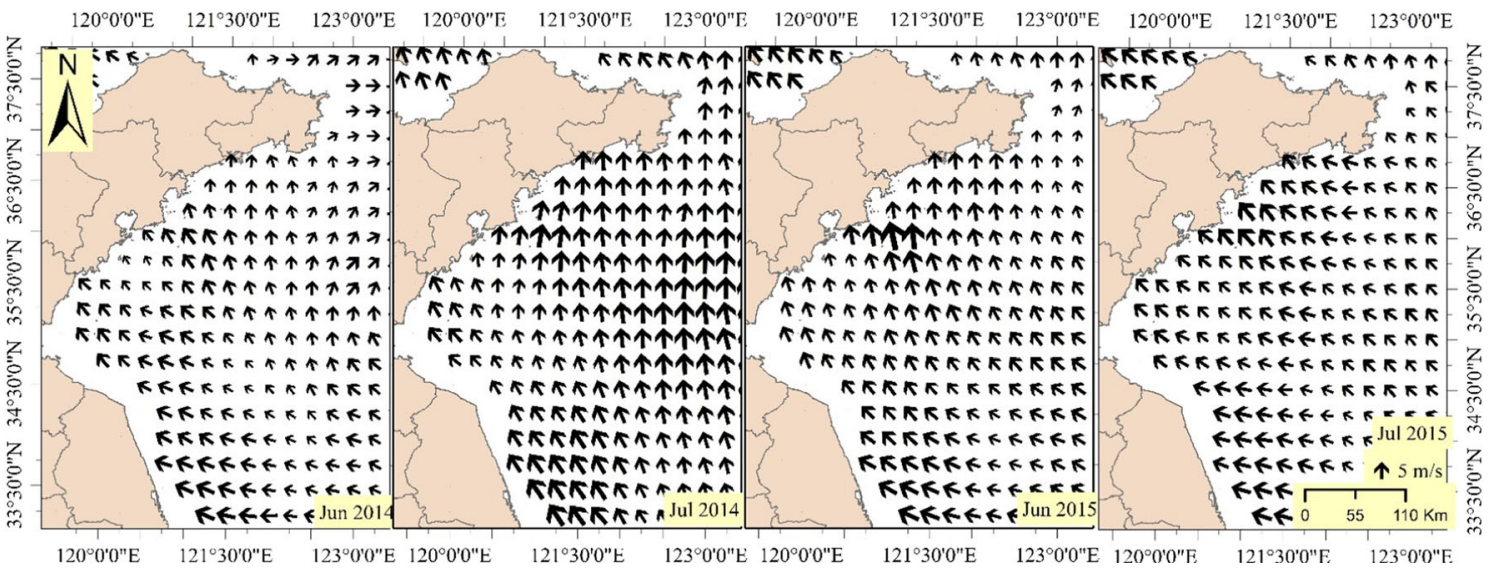

Fig. 9 Average wind data of June and July of Yellow Sea in 2014 and 2015 


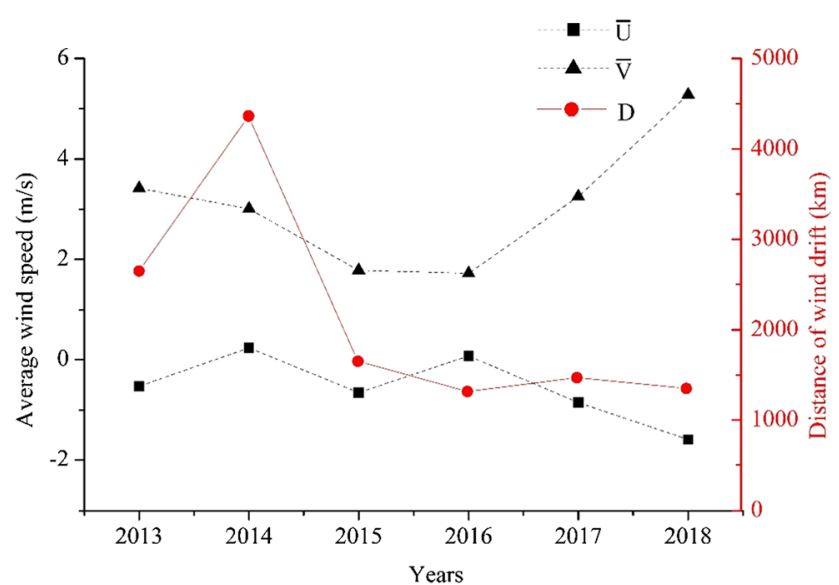

Fig. 10 The relationship between wind and drift position. $\bar{U}$ and $\bar{V}$ are the mean values of the east-west and north-south components of the regional average in the time $t$, and $D$ is the distance of the green tide front drifting from the starting point in $t$ time under the action of the component of the wind in the northeast direction $\left(\theta=45^{\circ}\right)$

current in Lunan coast, and Yellow Sea western coastal current (Fig. 11 current 2, 3,4, and 5), green tide will drift northeast in the Rongcheng coastal area. Combined with buoy drifting trajectory observations in 2012 (Bao et al. 2015), they have found that the buoy drifts mainly to the northeast after reaching the Rongcheng coastal waters and then it continues to move to the northeast after it has crossed $37.662^{\circ} \mathrm{N}$. So if

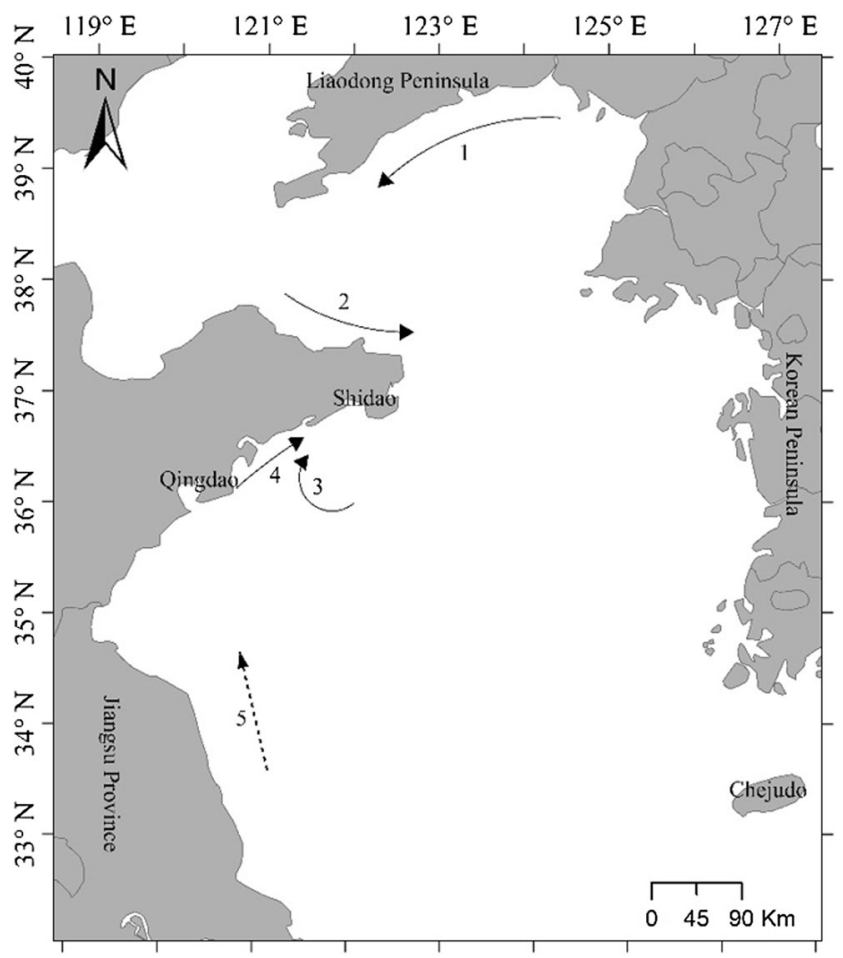

Fig. 11 Diagram of the coastal current system in the Yellow Sea. It was redrawn after reference (Wei et al. 2011), 1 (Liaonan coastal current), 2 (Lubei coastal current), 3 (mesoscale anticyclonic eddy in QingdaoShidao offshore, Qingdao cold water mass), 4 (northeastward current in Lunan coast), and 5 (northward current in Subei coast in summer) the green tide continues to drift northward, it needs to overcome great resistance from surface currents, unless there is strong weather convection to help it complete this process.

There is the small-scale green tide outbreak which has been reported in the north coastal area of Yantai and Weihai (37.41-37.66 $\left.\mathrm{N}, 121.13-122.13^{\circ} \mathrm{E}\right)$ since 2007 , and from the drifting of green tide in this paper, we can infer that the green tide in this coastal area is not from the southern Yellow Sea.

\section{Conclusion}

In the northernmost sea area affected by the green tide, the drift of the green tide from 2013 to 2018 has such a rule: the green tide drifts northward first and disappears from the sea surface from north to south after reaching the northernmost position. Before the green tide drifted to this sea area, there was no large-scale green tide in the Rongcheng coastal waters, indicating that the green tide had not yet settled in this sea area. The drift direction of green tide in this area is mainly northeast. The northernmost position from 2013 to 2018 is between $37.027^{\circ} \mathrm{N}$ and $37.662^{\circ} \mathrm{N}$, and the green tide has affected the northern Yellow Sea in 2014, but it did not drift to the coastal waters north of Yantai and Weihai. The drift of the green tide in this sea area is closely related to the wind, but not to the coverage area and days of existence of the green tide.

Acknowledgments We thank the US NASA for providing MODIS and SSW data and China Centre For Resources Satellite Data and Application for providing GF-1 data.

Funding information This work was supported by the National Natural Science Foundation of China [41876107], NSFC-Shandong joint fund project [U1706219], Basic Special Program of Ministry of Science and Technology [2014FY210600], and the Qingdao National Laboratory for Marine Science and Technology of China [2016ASKJ02].

\section{References}

Bao, M, Guan, W, Yang, Y, Cao, Z and others (2015) Drifting trajectories of green algae in the western Yellow Sea during the spring and summer of 2012. Estuar Coast Shelf Sci 163: 9-16 https://doi.org/ 10.1016/j.ecss.2015.02.009

Bentamy A, Croize-Fillon D, Perigaud C (2008) Characterization of ASCAT measurements based on buoy and QuikSCAT wind vector observations. Ocean Sci 4:265-274

Chen X, Zhang J, Cui T, Song P (2018) Extraction of the green tide drift velocity in the Yellow Sea based on GF-4. Acta Oceanol Sin 40:29 38 (In Chinese with English Abstract). https://doi.org/10.3969/j. issn.0253-4193.2018.01.004

Cui, T-W, Zhang, J, Sun, L-E, Jia, Y-J and others (2012) Satellite monitoring of massive green macroalgae bloom (GMB): imaging ability comparison of multi-source data and drifting velocity estimation. Int 
J Remote Sens 33: 5513-5527 https://doi.org/10.1080/01431161. 2012.663112

Dahlgren S, Kautsky L (2004) Can different vegetative states in shallow coastal bays of the Baltic Sea be linked to internal nutrient levels and external nutrient load? Hydrobiologia 514:249-258

Fleurence J, Gutbier G, Mabeau S, Leray C (1994) Fatty acids from 11 marine macroalgae of the French Brittany coast. J Appl Phycol 6: 527-532. https://doi.org/10.1007/BF02182406

Gao, S, Huang, J, Bai, T, Cao, Y and others (2014) Analysis on drifting path of green tides in the Yellow Sea in 2008 and 2009. Marine Sciences 86-90 (In Chinese with English abstract) https://doi.org/ 10.11759/hykx20111201003

$\mathrm{Hu}, \mathrm{C}, \mathrm{Li}, \mathrm{D}, \mathrm{Chen}, \mathrm{C}, \mathrm{Ge}, \mathrm{J}$ and others (2010) On the recurrent Ulva prolifera blooms in the Yellow Sea and East China Sea. J Geophys Res 115: https://doi.org/10.1029/2009jc005561

Hu P, Liu Y, Hou Y, Yin Y (2018) An early forecasting method for the drift path of green tides: a case study in the Yellow Sea, China. Int J Appl Earth Obs Geoinf 71:121-131. https://doi.org/10.1016/j.jag. 2018.05.001

Jin, S, Liu, Y, Sun, C, Wei, X and others (2018) A study of the environmental factors influencing the growth phases of Ulva prolifera in the southern Yellow Sea, China. Mar Pollut Bull 135: 1016-1025 https://doi.org/10.1016/j.marpolbul.2018.08.035

Lee JH, Pang I, Moon I, Ryu J (2011) On physical factors that controlled the massive green tide occurrence along the southern coast of the Shandong Peninsula in 2008: A numerical study using a particletracking experiment. J Geophysic Res:116. https://doi.org/10.1029/ $2011 \mathrm{jc} 007512$

Li, Y, Pan, L, Xiao, W, Hu, S and others (2014) Effect of wind on the drifting of green macroalgae in the Yellow Sea. Mar Environ Sci 33: 772-776 (In Chinese with English Abstract)

Li, J Y, Yang, F, Jin, L, Wang, Q and others (2018) Safety and quality of the green tide algal species Ulva prolifera for option of human consumption: a nutrition and contamination study. Chemosphere 210: 1021-1028 https://doi.org/10.1016/j.chemosphere.2018.07.076

Liu, D Y, Keesing, J K, He, P M, Wang, Z L and others (2013) The world's largest macroalgal bloom in the Yellow Sea, China: formation and implications. Estuarine Coastal and Shelf Science 129: 2 $10 \mathrm{https} / / /$ doi.org/10.1016/j.ecss.2013.05.021

Lopes RJ, Pardal MA, Marques JC (2000) Impact of macroalgal blooms and wader predation on intertidal macroinvertebrates experimental evidence from the Mondego estuary (Portugal). J Exp Mar Biol Ecol 249:165-179. https://doi.org/10.1016/S0022-0981(00)00202-1

Ma, Y, Xing, H, Song, X, Zhang, X and others (2010) The basic conditions and response measures of green tide outbreak in Yantai Golden Beach. Shandong Fisheries 27: 10-12 (In Chinese)

Nelson, T, Haberlin, K, Nelson, A, Ribarich, H and others (2008) Ecological and physiological controls of species composition in green macroalgal blooms. Ecology 89: 1287-1298 https://doi.org/ 10.1890/07-0494.1

Pang, S J, Liu, F, Shan, T F, Xu, N and others (2010) Tracking the algal origin of the Ulva bloom in the Yellow Sea by a combination of molecular, morphological and physiological analyses. Mar Environ Res 69: 207-215 https://doi.org/10.1016/j.marenvres.2009.10.007

Qiao F, Wang G, Lü X, Dai D (2011) Drift characteristics of green macroalgae in the Yellow Sea in 2008 and 2010. Chin Sci Bull 56:2236-2242. https://doi.org/10.1007/s11434-011-4551-7

Sheng, H, Guo, J, Wang, F (2018) Monitoring of green algae and analysis of spatial-temporal changes based on GOCI image data in Yellow Sea in 2015. Engineering of Surveying and Mapping 27: 52-58 (In Chinese with English abstract) https://doi.org/10.19349/j.cnki. issn1006-7949.2018.01.011
Son YB, Choi B-J, Kim YH, Park Y-G (2015) Tracing floating green algae blooms in the Yellow Sea and the East China Sea using GOCI satellite data and Lagrangian transport simulations. Remote Sens Environ 156:21-33. https://doi.org/10.1016/j.rse.2014.09.024

Song, X, Sun, G, Zhang, X, Ma, Y and others (2011) Likely causes of Enteromorpha linza green tide and its effect on the environmental factors in Yantai Cop Bay. J Saf Environ 11: 151-156 (In Chinese with English Abstract) https://doi.org/10.3969/j.issn.1009-6094. 2011.03.037

Song, X, Huang, R, Yuan, K, Zhao, Y and others (2015) Characteristics of the green tide disaster of east Shandong Peninsula offshore. Marine Environmental Science 34: 391-95 (In Chinese with English Abstract) https://doi.org/10.13634/j.cnki.mes.2015.03.012

Song, W, Wang, Z, Li, Y, Han, H and others (2019) Tracking the original source of the green tides in the Bohai Sea, China. Estuar Coast Shelf Sci 219: 354-362 https://doi.org/10.1016/j.ecss.2019.02.036

Wei Q, Yu Z, Ran X, Zan J (2011) Characteristics of the western coastal current of the Yellow Sea and its impacts on material transportation. Adv Earth Science 26:145-156 (In Chinese with English abstract)

Xing, Q G, Zheng, X Y, Shi, P, Hao, J J and others (2011) Monitoring "green tide" in the Yellow Sea and the East China Sea using multitemporal and multi-source remote sensing images. Spectroscop Spec Analysis 31: 1644-47 (Chinese) https://doi.org/10.3964/j. issn.1000-0593(2011)06-1644-04

Xu Q, Zhang H, Ju L, Chen M (2014) Interannual variability of Ulva prolifera blooms in the Yellow Sea. Int J Remote Sens 35:4099 4113. https://doi.org/10.1080/01431161.2014.916052

$\mathrm{Xu}, \mathrm{F}$, Gao, Z, Zheng, X, Ning, J and others (2017) Spatial and temporal distribution characteristic of green tides in the Yellow Sea in 2016 based on MODIS data. Marine Sciences 41: 80-84 (In Chinese with English Abstract) https://doi.org/10.11759/hykx20160922003

Yu R, Liu D (2016) Harmful algal blooms in the coastal waters of China: current situation, long-term changes and prevention strategies. Coast Sci Sustain Develop 31:1167-1174 (In Chinese with English Abstract). https://doi.org/10.16418/j.issn.1000-3045.2016.10.005

Yuan, D, Li, Y, Wang, B, He, L and others (2017) Coastal circulation in the southwestern Yellow Sea in the summers of 2008 and 2009. Cont Shelf Res 143: 101-117 https://doi.org/10.1016/j.csr.2017. 01.022

Zhang, J H, Huo, Y Z, Zhang, Z L, Yu, K F and others (2013) Variations of morphology and photosynthetic performances of Ulva prolifera during the whole green tide blooming process in the Yellow Sea. Mar Environ Res 92: 35-42 https://doi.org/10.1016/j.marenvres. 2013.08.009

Zhang, J, Huo, Y, Wu, H, Yu, K and others (2014) The origin of the Ulva macroalgal blooms in the Yellow Sea in 2013. Mar Pollut Bull 89: 276-283 https://doi.org/10.1016/j.marpolbul.2014.09.049

Zhao S (2014) Marine algae ecology. China ocean press, In

Zhao, J, Jiang, P, Qin, S, Liu, X and others (2015) Genetic analyses of floating Ulva prolifera in the Yellow Sea suggest a unique ecotype. Estuar Coast Shelf Sci 163: 96-102 https://doi.org/10.1016/j.ecss. 2015.05.027

Zhao, J, Jiang, P, Qiu, R, Ma, Y and others (2018) The Yellow Sea green tide: a risk of macroalgae invasion. Harmful Algae 77: 11-17 https:// doi.org/10.1016/j.hal.2018.05.007

Zhou M-J, Liu D-Y, Anderson DM, Valiela I (2015) Introduction to the special issue on green tides in the Yellow Sea. Estuar Coast Shelf Sci 163:3-8. https://doi.org/10.1016/j.ecss.2015.06.023

Publisher's note Springer Nature remains neutral with regard to jurisdictional claims in published maps and institutional affiliations. 